\title{
Waypoints on a Journey of Discovery: Mental Models in Human- Environment Interactions
}

\author{
$\underline{\text { Timothy Lynam }}^{1,2}, \underline{\text { Raphael Mathevet }}^{3,4}{ }^{\text {Michel Etienne }}{ }^{5}, \underline{\text { Samantha Stone-Jovicich }}^{1}$, Anne Leitch ${ }^{1}, \underline{\text { Nathalie Jones }}^{6}$, \\ $\underline{\text { Helen Ross }}^{6}, \underline{\text { Derick Du Toit }}^{7}, \underline{\text { Sharon Pollard }}^{7}$, Harry Biggs $^{8}$, and Pascal Perez $^{9}$
}

\begin{abstract}
Although the broad concept of mental models is gaining currency as a way to explore the link between how people think and interact with their world, this concept is limited by a theoretical and practical understanding of how it can be applied in the study of human-environment relationships. Tools and processes are needed to be able to elicit and analyze mental models. Because mental models are not directly observable, it is also important to understand how the application of any tools and processes affects what is measured. Equally important are the needs to be clear on the intent of the elicitation and to design the methods and choose the settings accordingly. Through this special edition, we explore how mental models are elicited using two approaches applied in two case-study regions. We analyze two approaches used in the Crocodile River catchment of South Africa: a graphically based approach, i.e., actors, resources, dynamics, and interactions (ARDI); and an interview- or text-based approach, i.e., consensus analysis (CA). A further experiment in the Rhone Delta (Camargue), France, enabled us to test a crossover between these two methods using ARDI methodology to collect data and CA to analyse it. Here, we compare and explore the limitations and challenges in applying these two methods in context and conclude that they have much to offer when used singly or in combination. We first develop a conceptual framework as a synthesis of key social and cognitive psychology literature. We then use this framework to guide the enquiry into the key lessons emerging from the comparative application of these approaches to eliciting mental models in the two case regions. We identify key gaps in our knowledge and suggest important research questions that remain to be addressed.
\end{abstract}

Key Words: ARDI; consensus analysis; France; mental models; social representations; South Africa; water management

\section{INTRODUCTION}

The concept of a mental model, an internal representation of external reality (Jones et al. 2011), has become part of the common lexicon of many scientists, business practitioners, and laypeople. The widespread use of the concept, however, masks notable differences in the meanings associated with it in terms of what mental models are, where they reside, and what people do with them (Jones et al. 2011). Some of the key differences in meanings associated with the concept of mental models include questions such as whether mental models reflect pre-existing, stable knowledge structures (Abel et al. 1998) or situation-specific and hence ephemeral knowledge structures (Greeno 1989, Smith and Semin 2004); whether mental models are narrative or image based (Kosslyn 1985, Macinnis and Price 1987, Moulton and Kosslyn 2009); the extent to which they are predominantly individual or collective knowledge structures (Mohammed et al. 2000, Mohammed and Dumville 2001, Ritchie-Dunham and Puente 2008); and whether mental models are embodied knowledge structures rather than being purely cognitive "in the head" knowledge structures (Barsalou 2009). Clusters of literature have developed around particular fields of enquiry and expertise, with varying degrees of conceptual and methodological overlap among them, e.g., research on team mental models and team performance (Converse et al. 1991, Mathieu et al. 2005, Smith-Jentsch et al. 2008), the roles of mental models in human reasoning (Johnson-Laird 2001, Byrne 2002, Johnson-Laird and Goldvarg-Steingold 2007, Byrne and Johnson-Laird 2009, Johnson-Laird 2010), and the large body of research on mental models in business and organizational environments (Senge 1990, 1992, Davison and Blackman 2005).

Despite the apparent importance of the mental model construct for understanding human-environment interactions, when our research for this special feature was initiated in 2006, there had not been a great deal of work in this field (Jones et al. 2011). As noted, the literature on the elicitation and analysis of mental models in other contexts or fields was extensive and incorporated a notable diversity of meanings, interpretations, and methods. What was lacking was a clear synthesis of theory and methods that was oriented toward mental models in human-environment interactions. A working group was established within an international research consortium called the Resilience Alliance (http://www.resalliance.org/), of which one purpose was to contribute to filling this gap through a practical application of methods and a review of aspects of the theory and methods associated with eliciting mental models. The results of this intent are reflected in the papers of this special feature. In this final paper of the special feature, we synthesize the key learning that emerged through the application of two mental model elicitation techniques in the

${ }^{1}$ CSIRO, ${ }^{2}$ Reflecting Society, ${ }^{3} \mathrm{CNRS}$, UMR 5175 CEFE, ${ }^{4}$ Stockholm Resilience Centre, ${ }^{5}$ INRA, Unité Ecodéveloppement, ${ }^{6}$ School of Agriculture and Food Sciences, The University of Queensland, ${ }^{7}$ AWARD, ${ }^{8}$ SANParks, ${ }^{9}$ University of Wollongong 
Crocodile River catchment, South Africa: a graphically based approach, referred to as ARDI (actors, resources, dynamics, and interactions; Etienne et al. 2011, Mathevet et al. 2011); and a verbal or text-based approach called consensus analysis (CA; Stone-Jovicich et al. 2011). In addition to this structured comparison, an allied research activity in France enabled us to test a cross-over between these two methods using the ARDI methodology to collect data and then CA to analyze them (Mathevet et al. 2011).

In seeking to synthesize the results of the papers in this special feature, we are faced with the daunting task of making sense of the diversity in meanings and interpretations associated with the concept of mental models. We wanted to know which definition or body of theory we should use and which was most suitable for our purpose of examining the two elicitation approaches that were used. The review by Jones et al. (2011) provides considerable guidance in relation to important conceptualizations of mental models, some of the associated concepts such as schema theory and how they might relate to mental models, and guidance on some of the methods used to elicit and analyze mental models. Here, we seek to add to the synthesis of Jones et al. (2011) by outlining why there is such a diversity of meanings associated with the mental models concept and what this diversity may reflect. We do this using social representations theory (Moscovici 1988, Wagner and Hayes 2005). In addition, we present a conceptual model to guide discussion of mental models and to aid interpretation of the papers in this special feature. In developing this synthesis, we have drawn on current cognitive and social psychology theory to develop a conceptualization of mental models that we then use as an aid to explore similarities and differences across the elicitation and analytical methods used. We conclude with a discussion of the implications of this working group's findings for future research and identify important gaps in the current understanding of mental models in humanenvironment interactions.

\section{A MENTAL MODEL CONCEPTUALIZATION}

\section{Mental models as social representations}

In their explanation of the differences between social cognition (the processes through which people seek to understand themselves and others) and social representation theories, Wagner and Hayes (2005:122) note, "It is the meaning of the things in, and for, the lives of people which makes them a social object." In this sense, the concept of a mental model is a social representation: a social object that has gone through "a historical social process of elaboration, communication and dissemination of knowledge systems" (Wagner and Hayes 2005:322). The mental model concept has become a widely accepted social object in the lives and communication of everyday people, e.g., reflected in creative writing since the mid- to late 1800 s, as well as an important concept across a diversity of academic disciplinary writing and theorizing
(Jones et al. 2011). It should come as no surprise therefore that the concept of a mental model "forms a structured, multidimensional portrayal of the subject area-that is, a whole set of statements related to one another as a theory-like construct... As such, a social representation is not a portrayal in the sense of a proposition which can be either true or false" (Wagner and Hayes 2005:121). Given this notion of a structured, multidimensional portrayal and the fact that we currently cannot observe mental models, we should expect, as Jones et al. (2011) identify in their review of the literature, that different individuals and academic disciplines stress different dimensions or sets of statements when using the mental models construct. We suggest that the cognitive dimensions of socialecological systems are a key, and yet little-discussed, component of these complex systems.

Structuralist theories of social representations (Abric 2001, Wagner and Hayes 2005) identify core and peripheral dimensions of representations. Core elements of a social representation are consensual and relatively stable, whereas the peripheral elements are the more individualized and dynamic components of the social representation. This distinction is useful in helping to make sense of the multidimensional subject area, which has come to be associated with the concept of mental models. Through our explorations of the literature, we identified three shared or core dimensions of the mental models concept. The first comprises relatively long-term and stable knowledge structures, often referred to as schema (Taylor and Crocker 1981, Jones et al. 2011). A second dimension relates to the situation in which the individual or group finds itself. The situation provides cues or stimuli that mediate cognition (Novak and Hoffman 2009); it also provides affordances (Gibson 1986, Greeno 1994) that extend the cognitive abilities of an individual in a given situation (Smith and Semin 2004, Yeh and Barsalou 2006). The third core dimension of the mental models concept relates to the attributes of the individual. Concepts such as an individual's need for cognition or a person's cognitive style are examples of elements of this third dimension (Cacioppo and Petty 1982, Childers et al. 1985, Stanovich and West 1998, Stanovich 1999).

\section{A conceptual framework}

As an aid to further discussion and reflection on what we have learned in relation to mental models, we developed a schematic representation of these core dimensions of the mental models concept and their possible relationships to one another (Fig. 1). We briefly justify the illustrated components and relationships through reference to key findings in the literature and then go on to use this simplified representation as a framework with which to discuss the contributions of the papers in this special feature. Each of these core dimensions is likely to contribute to observed variation and hence uncertainty in elicited mental models when looked at individually or across social groups. We therefore use the 
conceptualization (Fig. 1) to explore factors likely to contribute to uncertainty in elicited mental models in the context of human-environment interactions.

Fig. 1. Conceptual representation of the core dimensions of the mental models concept and their interrelationships. To simplify as much as possible, feedbacks such as those between mental models and knowledge structures are not shown.

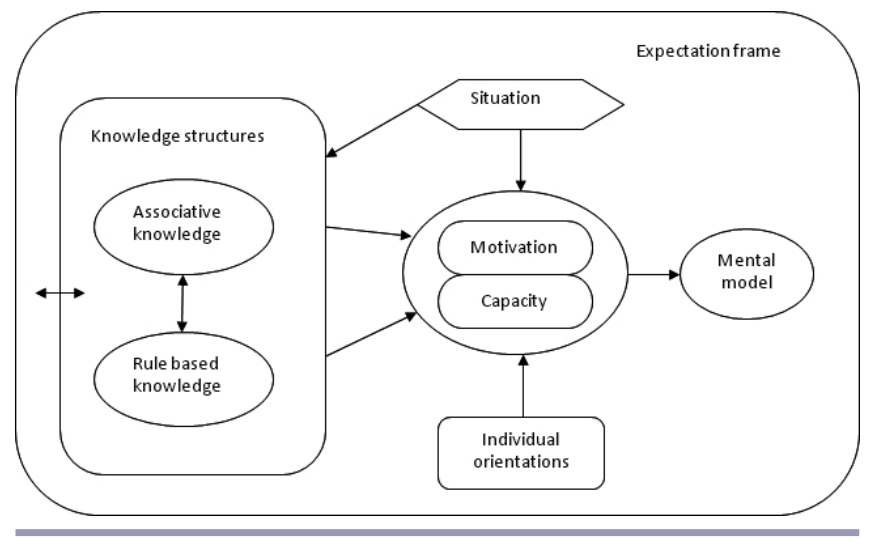

At a relatively coarse level of description, the conceptualization of mental models (Fig. 1) starts with the expectation frame, which can be thought of as a socially defined structure of "tacit theories about what exists, what happens, and what matters" in a given situation (Gitlin 1980). It thus prepares an individual for what to expect in a given situation, and hence cues what moods, motivations, and expectations with which an individual enters a situation. For example, whether a situation is framed as an academic enquiry or a management-oriented decision enquiry is likely to orient the individual toward particular moods, motivations, and expectations. These moods, motivations, and expectations are amenable to modification through the unfolding of the situation, but we argue that it is the individual's prior experience and framing that orients the individual toward particular cognitive states in relation to the given situation.

When an individual needs to perform some action (whether physical or cognitive) in a given situation, he/she draws on associative or rule-based knowledge structures as well as cues from the environment, e.g., available images, text, or natural objects, to compile a situation-specific mental model. The individual's cognitive orientations, motivations, and cognitive capacity mediate the translation and merger of knowledge from his/her knowledge structures with information from the situation to yield mental models that are suited to what the individual needs to do in the situation (Fig. 1). Thus, for example, in an environmental situation in which an individual who cared a great deal about the Crocodile River catchment was unhappy with how it was changing, had few other demands on his/her time, and was asked in a research situation to explain what caused problems with the river's flow, the individual might rely on his/her rule-based processing system to develop a mental model of the causes of problems with river flow. In a different situation, another individual who had been working within Crocodile River catchment management agencies for several decades and, while under great time pressure, was asked (by academics he/she considered irrelevant to the condition of the catchment) about stakeholders in the catchment, might answer rapidly, thus drawing on his/her associative knowledge systems.

The degree to which an individual's mental model draws on the knowledge from the associative or rule-based systems is contingent on the situation, the motivation of the individual to engage in thoughtful processing, and the cognitive capacity of the individual at that time (Smith and DeCoster 2000). When individuals are not motivated to think deeply about an issue, they tend to rely on the associative mode of thinking. Affect or situational expectations play an important role in weighting the likelihood of associative or rule-based modes of processing. Positive affect is likely to result in associative processing, whereas negative affect is more likely to result in use of the rule-based processing mode (Smith and DeCoster 2000, Kahneman 2011). When individuals face notable cognitive demands and are capacity limited, they tend to resort to the cognitively less demanding associative mode of processing. When individuals face novel situations, they are likely to use the rule-based processing mode with its greater flexibility and capacity for using counterfactual thinking (Smith and DeCoster 2000).

The relationship between existing knowledge structures and mental models has been a source of a number of conceptual differences in the literature dealing with mental models (Brewer 1987). As a simplification, the different perspectives may be placed on a continuum, with one end reflecting the perspective that mental models are pre-existing and relatively stable knowledge structures (Abel et al. 1998, Nersessian 2002), and the other end reflecting the perspective that mental models are relatively ephemeral knowledge structures created (from more stable knowledge structures) in relation to a specific situation (Brewer 1987). We position our conceptualization of mental models on the ephemeral end of the continuum: mental models are compiled as and when needed from pre-existing knowledge structures that are cued by the expectation of a situation (expectation frame) and the actual situation (Fig. 1). This positioning is consistent with recent literature on situated cognition (Smith and Semin 2004, 2007), on grounded or embodied cognition (Yeh and Barsalou 2006, Barsalou 2008, 2009), and on dual-process models in social cognition (Smith and DeCoster 2000, Kahneman 2011).

It might be argued that elements of what we have placed in the knowledge structures box of Fig. 1 could be called mental models. Following Smith and Semin (2004) and Barsalou 
(2008), we assert that a vital purpose of cognition is to support action in a given situation. The concept of mental models is a sense-making device that helps us think about and communicate processes of cognition and also helps us think through how to observe or measure peoples' conceptions of situations so that we might understand their responses. Thus, in the conceptualization we present here, a mental model only comes into being in relation to a specific situation for which it is required to support action. Mental models support action; associative and rule-based knowledge structures make up the basic knowledge elements that are drawn upon to compile the mental models.

Recent thinking on dual-process models in social cognition has important implications for how mental models are conceived and also for how they are elicited and measured. It is beyond the scope of this paper to review this literature; however, for the interested reader, the recent books by Kahneman (2011) and Stanovich (1999) as well as the review by Smith and DeCoster (2000) are useful overviews of existing theory and experimental work. Here, we draw heavily on the model presented by Smith and DeCoster (2000). We draw on the gross patterns of relationships reflected by these authors and do not explore the many subtleties and nuances of their model.

Dual-process theories propose that people use two cognitive processing systems: one is conceived as being a rapid and lowcognitive effort processing system often associated with automaticity, intuition, or common sense. The second processing system is conceived as being slower, requiring greater cognitive effort, and is associated with procedural or rule-based thinking (Novak and Hoffman 2009). In their model, Smith and DeCoster (2000) portray the rapid or associative processing system as reflecting stable, experientially based knowledge that is organized as networks of associations. The slower, more effortful, rule-based processing system is organized around formal or informal rules, which may be less stable than the experientially based associations of the associative knowledge system. Access to the information or knowledge in this rule-based system requires more controlled search and retrieval of rules and information. The two modes of processing are closely linked. Repeated use of particular relationships from the rule-based system may lead to these relationships becoming part of the more stable associative knowledge system; the relationships cued from the associative processing system may initially weight the rules to be used in rule-based processing. An unresolved issue in this body of theory is the degree to which these two processing systems operate simultaneously or sequentially. Smith and DeCoster (2000) argue that people use the two systems simultaneously.

Individuals have been found to reflect quite different cognitive styles (Stanovich 1999), have different requirements for cognition (Cacioppo and Petty 1982, Webster and Kruglanski 1994), and may be more visually or verbally oriented (Childers et al. 1985). These different cognitive dispositions are correlated with cognitive performance (Stanovich 1999) and may orient individuals more to using associative or rule-based modes of thinking.

Having briefly outlined this conceptualization of mental models, we now use the conceptualization to discuss the findings from the papers in the special feature. We pay particular attention to the contributions that each of these factors might make to elicited mental models.

\section{EXAMINING THE ELICITATION PROCESSES: ARDI AND CONSENSUS ANALYSIS}

We orient our comparisons of the results of mental model elicitation using ARDI and consensus analysis around the elements of the conceptual model of mental models (Fig. 1). We examine how each of the two methods enabled or constrained analysis of each of the components of mental models depicted in Fig. 1, with the exception that we do not explicitly discuss the expectation frame component of the model because we have no information on this component other than to note that there was likely to be a good deal of variation in the expectation frames of respondents. Different respondents were identified and asked to take part in the studies through direct contacts made by members of the South African team. These requests were framed to persuade the potential respondent to participate, and were less concerned with establishing a common expectation frame across respondents.

\section{Situations}

A range of studies have found that situational variables have a significant effect on the outcomes of individual behavior (Barker 1968, Baumeister and Tice 1985, Mesquita et al. 2010). Situational variables include those related to the physical setting, e.g., features of the physical setting, including space and time and the extent to which the setting is public or not, as well as characteristics of the subject such as their physical attributes, prior experience, and the cognitive and affective dynamics of the situation, e.g., the subject's information about the situation and its relevance to the subject's goals. The background knowledge of the individual such as his/her knowledge of other people, and what Baumeister and Tice (1985) call the "matrix of possibilities" relate to factors such as the range of options and freedom to choose among options available to the individual. Altogether, Baumeister and Tice (1985) identify 51 situation attributes that, across the studies they reviewed, had been found to influence individual behavior.

The studies presented as part of this special feature did not control for the effects of situational variables. We therefore do not have direct measures of the effects of situational 
variables on the elicited mental models. What follows is our subjective and qualitative analysis of the likely impacts of different situational variables on the resulting data.

An important situational difference between the research carried out in the Camargue (Mathevet et al. 2011) and that carried out in the Crocodile River catchment (Etienne et al. 2011, Stone-Jovicich et al. 2011) is the nature of the interactions between researchers and subjects. In the Camargue, the research was part of a sustained process of interaction between researchers and subjects; in the Crocodile River catchment, research interactions with subjects comprised single interaction events. In situations characterized by single-visit research processes, we suggest that individuals would be less motivated to engage in effortful thought, making responses based on associative knowledge systems more likely. In contrast, sustained relationships and interactions between researchers and practitioners on issues that the practitioners cared about would provide strong motivation for the subjects to carefully consider their responses. Hence, the mental models that were expressed in the Camargue were likely to draw strongly on rule-based knowledge structures. All else being equal, when people care strongly about a subject, they will be motivated toward accuracy in their understanding of the subject; the desire for accuracy is often associated with rule-based knowledge structures and processing (Chaiken and Stangor 1987, Chaiken et al. 1996, Smith and DeCoster 2000).

This observation also relates to the way the research was framed in each situation. In the Crocodile River catchment, where the ARDI approach was used, the research process was framed to respondents as a question about their thoughts around water resource use and management in the catchment (Etienne et al. 2011). In contrast, in the second stage of the consensus analysis approach, respondents were asked to select either yes or no responses to lists of stakeholders or causes of problems, as well as to sort concepts about consequences and future priorities (Stone-Jovicich et al. 2011). These different framings, i.e., the ARDI approach that focused on thinking, and the consensus analysis approach that focused on associations among concepts and questions, may well have cued rule-based and associative knowledge structures, respectively. We suggest that the consensus analysis approach as applied in South Africa does not so much elicit mental models as the more fundamental knowledge structures of Fig. 1. The application in France, while not true to the formal cultural consensus model, does illustrate the application of the informal consensus analysis model and provides a measure of consensus in the mental models of participants, mental models that we have suggested draw heavily on rule-based knowledge structures.

In addition, half of the Camargue respondents had been interacting with each other in relation to water management in the Rhone Delta, in both formal and informal settings over a number of years. Theirs was a history of repeated interactions in relation to the common environmental domain. There was likely considerable "elaboration, communication and dissemination of knowledge systems" (Wagner and Hayes 2005:322). This would lead us to predict a relatively high transfer level of rule-based knowledge into the associative or experiential knowledge systems of the longer-term water board members, with greater consensus and stability in their associative knowledge. Although we cannot differentiate between associative and rule-based knowledge structures in the mental models elicited from Camargue respondents, there was greater consensus among long-term water board members relative to newcomers and outsiders (Mathevet et al. 2011).

This sort of sustained relationship with a common management problem was not the situation in the Crocodile River catchment in South Africa. That situation reflected a more fragmented set of interactions, with only a few of the interviewed irrigators or conservationists interacting frequently through formal or informal settings. In addition, when they occurred, these interactions were likely to focus on a number of different problem domains, and not specifically on the Crocodile River catchment.

Implementation of the ARDI process in the French case involved individual interviews, either at the respondents' home or place of work (Mathevet et al. 2011). In South Africa, the respondents selected for the ARDI approach were interviewed in one of two formal meeting room locations. Respondents selected for the consensus analysis interview process (stage two) were either interviewed in national park offices, their place of work, or their home. In some cases, these respondents were highly time constrained, whereas in other cases, there were significant situational cues available to them. We therefore have no explicit measures of the effects of these different situational variables on the elicited mental models in either the South African or French cases. More recent, but as yet unpublished, research by one of the authors clearly demonstrates situational effects on elicited mental models (Jones 2012).

\section{Knowledge structures}

The two data collection instruments used as part of the consensus analysis' second stage in the Crocodile River catchment did not lend themselves, and were not designed, to elicit rule-based knowledge structures. The yes/no and pilesort instruments were more likely to elicit fundamental knowledge structures rather than mental models as we have defined them (Fig. 1) because this is what the cultural consensus technique is designed to measure (Weller 2007). In contrast, the ARDI process is designed to provide a framework for respondents to think through and describe the state (including the dynamic state) of a given social-ecological system (Etienne et al. 2011). The ARDI process is therefore 
likely to result in mental models that draw heavily on rulebased knowledge structures.

The application of the ARDI process in the Camargue provided an interesting hybrid from an analytical perspective but not from an elicitation perspective: elicitation was oriented toward rule-based knowledge structures using the ARDI process, whereas analysis was oriented toward understanding the degree to which elements of the elicited mental models were shared among the subjects.

\section{Motivations and capacities}

Measures of the motivations or capacities of individuals responding to each of the tasks were not made in any of the cases. We suspect that different groups may have had different motivations to engage with the research. The work in the Camargue, for example, as part of an ongoing research activity, was likely to provide strong incentives for individuals to engage with the research process. This was less true in the South African situation, where interactions between researchers and respondents were framed as a single research or data collection event. Some respondents were observed to be highly time constrained in the consensus analysis component of the South African research, which could result in their relying more on associative rather than rule-based knowledge structures. For many respondents in the South African case, there appeared to be a political motivation to engage with the research. As Du Toit et al. (2011) noted, the research was conducted during a period of time in which the organizations and structures associated with implementing the water act were being developed and bedded down. It was thus likely that several of the respondents saw this research project as a means to achieve political ends. We suggest that in these situations, respondents were likely to be more reliant on rulebased than associative knowledge structures.

As far as we were able to observe in the South African situation and in the Camargue, individual respondents could focus almost exclusively on the task at hand. It was unlikely therefore that respondents faced situations of high demands on their cognitive capacity; hence, the observation that associative knowledge structures are often used in situations of high cognitive load was not likely to apply (Smith and DeCoster 2000). However, some respondents taking part in the ARDI process, both in South Africa and France, noted that the task was highly taxing. Where respondents were taxed in this way, our model predicts they would be motivated to rely more on associative than rule-based knowledge structures.

\section{Mental models}

To elicit mental models effectively in relation to a given purpose, it should be clear from the preceding discussion that an elicitation process needs to be designed in relation to what is being sought: fundamental knowledge structures, deeply thought mental models, or spur of the moment mental models (Fig. 1). In regard to the work carried out in South Africa and
France, we were only partially aware of these different components of mental models. As a consequence, we either did not take measurements that enabled us to identify the contributions of these different components or we were unsuccessful in holding elements such as situations constant. One of the objectives of this special feature and synthesis paper is to provide a synthesis of the literature and our experiences to support a greater awareness among future researchers of these different components of mental models and hence their influence as sources of variability in elicited mental models across time or groups.

Our conceptualization of mental models suggests that we would find greater stability and consensus in the associative knowledge elements of mental models because these are the commonly held (consensual) and experientially based knowledge components. Data from the Camargue (Mathevet et al. 2011) provide some evidence to support this prediction. Owing to the necessity of frequent interaction and hence experience among important stakeholder groups, we expect that the knowledge of stakeholders would be relatively stable and consensual. Among the Camargue respondents, there was strong agreement among most respondents as to who the key stakeholders in the system were (Mathevet et al. 2011). In contrast, and as might be predicted from our conceptual model and the conceptualization of Smith and DeCoster (2000), more complex phenomena are unlikely to be directly experienced; mental models of these phenomena are thus likely to draw on rule-based knowledge structures to a greater extent and hence be more individually variable and unstable. Consistent with this expectation was the lack of consensus in the mental models of interactions among actors, resources, and dynamics in the mental models of respondents in the Camargue (Mathevet et al. 2011).

Overall, the consensus analysis approach to eliciting mental models used in the South African case was well oriented to measure what it was designed to measure: shared associative or rule-based knowledge structures. In contrast, the ARDI approach used in South Africa was well suited to eliciting elements of rule-based knowledge structures. Although the ARDI approach that combines development of the diagrammatic representation with discussion of the meanings and associations provides a rich narrative associated with the mental models, no simple way of analyzing these has yet been implemented.

Our conceptual model and the results from the papers in this special feature pose some significant challenges in relation to eliciting mental models associated with human-environment interactions. One of the most notable of these challenges is the potential influence of the situation on the elicited mental model. Social psychology theorists argue convincingly that people generate situated mental models that are oriented toward situated action (Smith and Semin 2004, Barsalou 
2009). To understand the mental models of individuals or groups in a research situation, we need to understand how they construed or framed the research situation. It is an open question as to how similar the mental models derived in a research situation would be to those used in a different action situation such as planning or taking a vote on a set of actions. Differences in what people say they will do versus what they actually do have been well documented (Argyris and Schön 1978). In eliciting mental models, we therefore need to be cognizant that what has been elicited may not at all reflect the mental models that would be used in the actual action situations in which we were interested.

\section{CONCLUSIONS}

The concept of a mental model is used across a diverse spectrum of academic disciplines. Across this spectrum, the concept may have quite different meanings. In part, because mental models are unobservable, there is no objective reality to provide feedbacks that might iterate thinking and communication toward a more accurate representation of a mental model. Mental models therefore become what our specific academic cultures have come to think of them as through the processes of "elaboration, communication and dissemination" (Wagner and Hayes 2005:322). There is no one true conception of a mental model, and some researchers question the existence of mental models altogether (Barsalou 2003, Barsalou et al. 2003). Why then have we gone to all the trouble of developing a conceptual model of mental models and of exploring processes for the measurement of mental models? Because the concept of a mental model is useful: it provides a sense-making device that we can use to think and communicate about how people think and communicate about human-environment interactions. To distort Box's oft-quoted dictum: our mental models of mental models are wrong, but some of them, in some instances, may be useful. In presenting the conceptualization (Fig. 1) and using it to examine the papers in this special feature, we have sought to increase the utility of the mental models concept in the realm of humanenvironment interactions. The conceptualization of Fig. 1 builds on key bodies of social psychology and cognitive science theory that we hope will be both a useful (albeit highly simplified) synthesis of some relevant parts of this literature as well as increasing the utility of the mental models concept for future thought and communication.

From reflection upon the South African and Camargue research and from the perspective of the conceptual model (Fig. 1), we have identified a number of important lessons and a number of challenges.

One important lesson relates to the interconnections between situations, respondents, and elicited mental models. Elicited mental models can only really be understood as part of a situation. To understand the mental model, we need to know about the situation: They are inseparable and should not be treated otherwise. Related to this need for situational knowledge is the recognition of the need to know about the individual, his/her cognitive orientations, and his/her cognitive capacity constraints as they relate to the situation.

A second important lesson relates to clarifying what it is we seek to elicit and why. We need to be clear on whether we want to know about associative or rule-based knowledge structures or if we want to know about the combinations of these that are the basis of elicited mental models. Depending on what we are after, we can then use elicitation techniques that will capture the desired information. We need to recognize that if we seek to identify more stable and consensual elements of mental models, then our data collection should focus more on capturing associative knowledge structures. Based on our experiences with eliciting mental models using a consensus analysis approach and the ARDI approach, we think that mixed methods approaches that capture both associative and rulebased knowledge structures are likely to be the most informative when investigating mental models of humanenvironment interactions.

There are many unanswered questions and important challenges that need to be addressed to improve our collective ability to elicit and analyze mental models in the context of human-environment interactions. First, we know little about the relationships between elicited mental models and actions in a given action situation. It is difficult to imagine simple, field-based processes to explore these relationships. Investigations of this sort may be able to build on the extensive knowledge base developed around attitude-behavior relationships (Ajzen 2001, Ajzen and Fishbein 2005, Crano and Prislin 2006). However, unraveling the complex relationships associated with mental models as we construe them is likely to require significant research investment and may be most easily addressed in laboratory experimental settings in the preliminary stages, taking into account our previous comments in relation to mental models and action situations. It may be fruitful to explore narrative-based approaches that analyze an individual's narrative of his/her experiences, including his/her descriptions of the situations in which these experiences occurred.

A second challenge comprises the development and implementation of simple measurement instruments to identify the effects on the elicited mental models of respondent motivation, capacity, and orientation. Although a number of these measures exist, their length makes it difficult to envisage their use in association with a mental model elicitation activity (Lohman and Bosma 2002, Mayer et al. 2007). Field-based research will be challenged to develop meaningful measures of these factors that are implementable without overwhelming the focus of the study.

We have paid scant attention to the effects of group processes on elicited mental models. The results of the research in the 
Camargue (Mathevet et al. 2011) indicate that group interactions lead to more consensual mental models. This finding is consistent with research in other fields (Mohammed et al. 2010). There is considerable literature on group processes and how these affect group outcomes (Hogg and Tindale 2003). Group situations such as those reflected in the papers of this special issue are fundamentally different to situations involving individuals. Although the conceptual model we present (Fig. 1) might be useful as a preliminary guide for research in these contexts, the additional complexities associated with group processes and dynamics would make the situation much more difficult to work with. In applied contexts, the safe strategy is likely to be to create as closely as possible the actual situation in which mental models are to be used and to seek to elicit mental models in those situations. If decisions are to be made through group processes and a mental models approach is used to understand these decisions, then elicitation processes designed to work with group situations would be needed. The ARDI process was designed as a group elicitation process (Étienne 2006) and could prove useful in group processes; however, the ARDI data-collection process is unlikely to be akin to the actual decision processes for any real world decision making.

The widespread use of the concept of mental models suggests that scholars and practitioners alike are aware of the need to take the cognitive dimensions of people and social systems into consideration when investigating or managing socialecological systems. Culture, or "the set of learned and shared beliefs and behaviors...of a group" (Weller 2007), is a vitally important component of the structure of social systems that therefore contributes both to enabling and constraining social change (Archer 1995). We hope that through the papers of this special feature and through this synthesis paper we have contributed to a more informed understanding of key elements of the theory associated with mental models as well as some tools for working with mental models and their associated knowledge structures.

Responses to this article can be read online at: http://www.ecologyandsociety.org/vol17/iss3/art23/ responses/

\section{Acknowledgments:}

We gratefully acknowledge comments and suggestions from Zoe Leviston, Kirsten Maclean, and Nick Abel, which helped improve the paper. In addition, two anonymous reviewers and Sarah Funkhouser provided useful suggestions for improving the paper. The CSIRO members of the mental models group are grateful to all participants in the research and the timely supportfrom CSIRO's Complex Systems Science Program and the Resilience Alliance. The French members of the mental models group thank all stakeholders for participating in the study. This work took place in the GIZCAM project and was conducted with financial support from the French Ministry of Ecology (LITEAU II program) and the SETER Project supported by the Agropolis Fondation.

\section{LITERATURE CITED}

Abel, N., H. Ross, and P. Walker. 1998. Mental models in rangeland research, communication and management. Rangeland Journal 20(1):77-91. http://dx.doi.org/10.1071/RJ 9980077

Abric, J.-C. 2001. A structural approach to social representations. Pages 42-47 in K. Deaux and G. Philogène, editors. Representations of the social: bridging theoretical traditions. Blackwell, Oxford, UK.

Ajzen, I. 2001. Nature and operation of attitudes. Annual Review of Psychology 52:27-58. http://dx.doi.org/10.1146/an nurev.psych.52.1.27

Ajzen, I., and M. Fishbein. 2005. The influence of attitudes on behavior. Pages 173-221 in D. Albarracín, B. T. Johnson, and M. P. Zanna, editors. The handbook of attitudes. L. Erlbaum Associates, Mahwah, New Jersey, USA.

Archer, M.S. 1995. Realist social theory: the morphogenetic approach. Cambridge University Press, Cambridge, UK.

Argyris, C., and D. A. Schön. 1978. Organizational learning: a theory of action perspective. Addison-Wesley, Reading, Massachusetts, USA. http://dx.doi.org/10.2307/40183951

Barker, R. G. 1968. Ecological psychology: concepts and methods for studying the environment of human behavior. Stanford University Press, Stanford, California, USA.

Barsalou, L. 2003. Situated simulation in the human conceptual system. Language and Cognitive Processes 18 (5-6):513-562. http://dx.doi.org/10.1080/01690960344000026

Barsalou, L. W. 2008. Grounded cognition. Annual Review of Psychology 59:617-645. http://dx.doi.org/10.1146/annurev.ps ych.59.103006.093639

Barsalou, L. W. 2009. Simulation, situated conceptualization, and prediction. Philosophical Transactions of the Royal Society B: Biological Sciences 364:1281-1289. http://dx.doi.o rg/10.1098/rstb.2008.0319

Barsalou, L. W., W. K. Simmons, A. K. Barbey, and C. D. Wilson. 2003. Grounding conceptual knowledge in modalityspecific systems. Trends in Cognitive Sciences 7(2):84-91. http://dx.doi.org/10.1016/S1364-6613(02)00029-3

Baumeister, R. F., and D. M. Tice. 1985. Toward a theory of situational structure. Environment and Behavior 17 (2):147-192. http://dx.doi.org/10.1177/0013916585172001 
Brewer, W. F. 1987. Schemas versus mental models in human memory. Pages 187-197 in P. Morris, editor. Modelling cognition. Wiley, Chichester, UK.

Byrne, R. M. J. 2002. Mental models and counterfactual thoughts about what might have been. Trends in Cognitive Sciences 6(10):426-431. http://dx.doi.org/10.1016/S1364-6613 (02)01974-5

Byrne, R. M. J., and P. N. Johnson-Laird. 2009. 'If' and the problems of conditional reasoning. Trends in Cognitive Sciences 13(7):282-287. http://dx.doi.org/10.1016/j.tics.2009 $\underline{.04 .003}$

Cacioppo, J. T., and R. E. Petty. 1982. The need for cognition. Journal of Personality and Social Psychology 42(1):116-131. http://dx.doi.org/10.1037/0022-3514.42.1.116

Chaiken, S., R. Giner-Sorolla, and S. Chen. 1996. Beyond accuracy: defense and impression motives in heuristic and systematic information processing. Pages 553-578 in P. M. Gollwitzer and J. A. Bargh, editors. The psychology of action: linking cognition and motivation to behavior. Guilford Press, New York, New York, USA.

Chaiken, S., and C. Stangor. 1987. Attitudes and attitude change. Annual Review of Psychology 38:575-630. http://dx.d oi.org/10.1146/annurev.ps.38.020187.003043

Childers, T. L., M. J. Houston, and S. E. Heckler. 1985. Measurement of individual differences in visual versus verbal information processing. Journal of Consumer Research 12 (2):125-134. http://dx.doi.org/10.1086/208501

Converse, S. A., J. A. Cannon-Bowers, and E. Salas. 1991. Team member shared mental models: a theory and some methodological issues. Proceedings of the Human Factors and Ergonomics Society Annual Meeting 35(19):1417-1421. http: //dx.doi.org/10.1177/154193129103501917

Crano, W. D., and R. Prislin. 2006. Attitudes and persuasion. Annual Review of Psychology 57:345-374. http://dx.doi.org/1 0.1146/annurev.psych.57.102904.190034

Davison, G., and D. Blackman. 2005. The role of mental models in the development of knowledge management systems. International Journal of Organisational Behaviour 10(6):757-769. [online] URL: http://www.usq.edu.au/extrafiles/ business/journals/HRMJournal/InternationalArticles/ Volume10Ageing/DavisonBlackmanVol10No6.pdf.

Du Toit, D. R., H. Biggs, and S. Pollard. 2011. The potential role of mental model methodologies in multistakeholder negotiations: integrated water resources management in South Africa. Ecology and Society 16(3): 21. http://dx.doi.org/10.57 51/ES-04237-160321

Étienne, M. 2006. Companion modelling: a tool for dialogue and concertation in Biosphere Reserves. Pages 44-52 in M.
Bouamrane, editor. Biodiversity and stakeholders: concertation itineraries. Biosphere Reserves Technical Notes 1. UNESCO, Paris, France. [online] URL: http://unesdoc.unesco.org/image s/0014/001465/146566e.pdf.

Etienne, M., D. R. Du Toit, and S. Pollard. 2011. ARDI: a coconstruction method for participatory modeling in natural resources management. Ecology and Society 16(1): 44. [online] URL: http://www.ecologyandsociety.org/vol16/iss1/ $\underline{\operatorname{art} 44 / .}$

Gibson, J. J. 1986. The ecological approach to visual perception. L. Erlbaum Associates, Hillsdale, New Jersey, USA.

Gitlin, T. 1980. The whole world is watching: mass media in the making and unmaking of the New Left. University of California Press, Berkeley, California, USA.

Greeno, J. G. 1989. Situations, mental models, and generative knowledge. Pages 285-318 in D. Klahr and K. Kotovsky, editors. Complex information processing: the impact of Herbert A. Simon. L. Erlbaum Associates, Hillsdale, New Jersey, USA.

Greeno, J. G. 1994. Gibson's affordances. Psychological Review 101(2):336-342. http://dx.doi.org/10.1037/0033-295X .101 .2 .336

Hogg, M. A., and R. S. Tindale, editors. 2003. Blackwell handbook of social psychology: group processes. Paperback edition. Blackwell, Oxford, UK.

Johnson-Laird, P. N. 2001. Mental models and deduction. Trends in Cognitive Sciences 5(10):434-442. http://dx.doi.org /10.1016/S1364-6613(00)01751-4

Johnson-Laird, P. N. 2010. Mental models and human reasoning. Proceedings of the National Academy of Sciences 107(43):18243-18250. http://dx.doi.org/10.1073/pnas.1012933107

Johnson-Laird, P. N., and E. Goldvarg-Steingold. 2007. Models of cause and effect. Pages 167-188 in W. Schaeken, A. Vandierendonck, W. Schroyens, and G. d'Ydewalle, editors. The mental models theory of reasoning: refinements and extensions. L. Erlbaum Associates, Mahwah, New Jersey, USA.

Jones, N. A. 2012. Mental models of natural resource systems: a comparison of elicitation procedures. University of Queensland, Brisbane, Australia.

Jones, N. A., H. Ross, T. Lynam, P. Perez, and A. Leitch. 2011. Mental models: an interdisciplinary synthesis of theory and methods. Ecology and Society 16(1): 46. [online] URL: http:/ /www.ecologyandsociety.org/vol16/iss1/art46/.

Kahneman, D. 2011. Thinking, fast and slow. Farrar, Straus and Giroux, New York, New York, USA. 
Kosslyn, S. M. 1985. Mental representation. Bulletin of the British Psychological Society 38:A68-A68.

Lohman, D. F., and A. Bosma. 2002. Using cognitive measurement models in the assessment of cognitive styles. Pages 134-154 in H. I. Braun, D. N. Jackson, and D. E. Wiley, editors. Under construction: the role of constructs in psychological and educational measurement. L. Erlbaum Associates, Mahwah, New Jersey, USA.

MacInnis, D. J., and L. L. Price. 1987. The role of imagery in information processing: review and extensions. Journal of Consumer Research 13(4):473-491. http://dx.doi.org/10.1086 1209082

Mathevet, R., M. Etienne, T. Lynam, and C. Calvet. 2011. Water management in the Camargue Biosphere Reserve: insights from comparative mental models analysis. Ecology and Society 16(1): 43. [online] URL: http://www.ecologyand society.org/vol16/iss1/art43/.

Mathieu, J. E., T. S. Heffner, G. F. Goodwin, J. A. CannonBowers, and E. Salas. 2005. Scaling the quality of teammates' mental models: equifinality and normative comparisons. Journal of Organizational Behavior 26(1):37-56. http://dx.doi. org/10.1002/job.296

Mayer, J. D., M. A. Faber, and X. Y. Xu. 2007. Seventy-five years of motivation measures (1930-2005): a descriptive analysis. Motivation and Emotion 31(2):83-103. http://dx.doi. org/10.1007/s11031-007-9060-2

Mesquita, B., L. F. Barrett, and E. R. Smith. 2010. The mind in context. Guilford Press, New York, New York, USA.

Mohammed, S., and B. C. Dumville. 2001. Team mental models in a team knowledge framework: expanding theory and measurement across disciplinary boundaries. Journal of Organizational Behavior 22(2):89-106. http://dx.doi.org/10.1 $\underline{002 / j o b .86}$

Mohammed, S., L. Ferzandi, and K. Hamilton. 2010. Metaphor no more: a 15-year review of the team mental model construct. Journal of Management 36(4):876-910. http://dx.d oi.org/10.1177/0149206309356804

Mohammed, S., R. Klimoski, and J. R. Rentsch. 2000. The measurement of team mental models: we have no shared schema. Organizational Research Methods 3(2):123-165. htt p://dx.doi.org/10.1177/109442810032001

Moscovici, S. 1988. Notes towards a description of social representations. European Journal of Social Psychology 18:211-250.

Moulton, S. T., and S. M. Kosslyn. 2009. Imagining predictions: mental imagery as mental emulation. Philosophical Transactions of the Royal Society B: Biological
Sciences 364(1521):1273-1280. http://dx.doi.org/10.1098/rstb .2008 .0314

Nersessian, N. J. 2002. The cognitive basis of model-based reasoning in science. Pages 133-152 in P. Carruthers, S. Stich, and M. Siegal, editors. The cognitive basis of science. Cambridge University Press, Cambridge, UK. http://dx.doi.o rg/10.1017/CBO9780511613517.008

Novak, T. P., and D. L. Hoffman. 2009. The fit of thinking style and situation: new measures of situation-specific experiential and rational cognition. Journal of Consumer Research 36(1):56-72. http://dx.doi.org/10.1086/596026

Ritchie-Dunham, J. L., and L. M. Puente. 2008. Strategic clarity: actions for identifying and correcting gaps in mental models. Long Range Planning 41(5):509-529. http://dx.doi.o rg/10.1016/j.lrp.2008.06.006

Senge, P. M. 1990. The fifth discipline: the art and practice of the learning organization. Doubleday, New York, New York, USA.

Senge, P. M. 1992. Mental models. Strategy and Leadership 20(2):4-44. http://dx.doi.org/10.1108/eb054349

Smith, E. R., and J. DeCoster. 2000. Dual-process models in social and cognitive psychology: conceptual integration and links to underlying memory systems. Personality and Social Psychology Review 4(2):108-131. http://dx.doi.org/10.1207/S 15327957PSPR0402_01

Smith, E. R., and G. R. Semin. 2004. Socially situated cognition: cognition in its social context. Advances in Experimental Social Psychology 36:53-117. http://dx.doi.org /10.1016/S0065-2601(04)36002-8

Smith, E. R., and G. R. Semin. 2007. Situated social cognition. Current Directions in Psychological Science 16(3):132-135. http://dx.doi.org/10.1111/j.1467-8721.2007.00490.x

Smith-Jentsch, K. A., J. A. Cannon-Bowers, S. I. Tannenbaum, and E. Salas. 2008. Guided team self-correction: impacts on team mental models, processes, and effectiveness. Small Group Research 39(3):303-327. http://dx.doi.org/10.11 77/1046496408317794

Stanovich, K. E. 1999. Who is rational? Studies of individual differences in reasoning. L. Erlbaum Associates, Mahwah, New Jersey, USA.

Stanovich, K. E., and R. F. West. 1998. Individual differences in rational thought. Journal of Experimental Psychology: General 127(2):161-188. http://dx.doi.org/10.1037/0096-344 5.127.2.161

Stone-Jovicich, S. S., T. Lynam, A. Leitch, and N. A. Jones. 2011. Using consensus analysis to assess mental models about water use and management in the Crocodile River catchment, 
South Africa. Ecology and Society 16(1): 45. [online] URL: http://www.ecologyandsociety.org/vol16/iss1/art45/.

Taylor, S. E., and J. Crocker. 1981. Schematic bases of social information processing. Pages 89-134 in E. T. Higgins, C. P. Herman, and M. P. Zanna, editor. Social cognition: the Ontario symposium. L. Erlbaum Associates, Hillsdale, New Jersey, USA.

Wagner, W., and N. Hayes. 2005. Everyday discourse and common sense: the theory of social representations. Palgrave Macmillan, New York, New York, USA.

Webster, D. M., and A. W. Kruglanski. 1994. Individual differences in need for cognitive closure. Journal of Personality and Social Psychology 67(6):1049-1062. http://d x.doi.org/10.1037/0022-3514.67.6.1049

Weller, S. C. 2007. Cultural consensus theory: applications and frequently asked questions. Field Methods 19(4):339-368. http://dx.doi.org/10.1177/1525822X07303502

Yeh, W., and L. W. Barsalou. 2006. The situated nature of concepts. American Journal of Psychology 119(3):349-384. http://dx.doi.org/10.2307/20445349 